\title{
O USO DA LÍNGUA INGLESA COMO FERRAMENTA DE ENSINO E APRENDIZAGEM NA EDUCAÇÃO AMBIENTAL: UMA EXPERIÊNCIA NA ESCOLA AGOSTINHA DILL- CONDOR, RS
}

\author{
Alexandra Freitas de Mello', Paulo Edelvar Correa Peres ${ }^{2}$ \\ 'Aluna do Curso de Pós-Graduação Lato Sensu em Educação Ambiental da Universidade Federal de \\ Santa Maria (UFSM). E-mail: alefmello@hotmail.com \\ 2 Professor Associado do Departamento de Microbiologia e Parasitologia do Centro de Ciências da \\ Saúde da Universidade Federal de Santa Maria (UFSM). Cirurgião Dentista, formado pela \\ Universidade Federal de Santa Maria (UFSM) em 1984, Odontopediatra, Especialista em Saúde \\ Coletiva, Mestre e Doutor em Biologia e Patologia Buco-Dental pela Universidade Estadual de \\ Campinas (UNICAMP), onde realizou Estágio de Pós-Doutorado e atuou como Pesquisador \\ Colaborador junto ao Programa de Pós-Graduação em Odontologia, Área de Bioquímica, com \\ ênfase em Cariologia. Integra a equipe Editorial da Revista Odonto Ciência - Journal of Dental \\ Science, da Pontifícia Universidade Católica do Rio Grande do Sul (PUCRS). É pesquisador \\ responsável pelo LAPEMICRO-UFSM, Laboratório de Pesquisa em Microbiologia Oral e Geral, onde \\ coordena trabalhos de Pesquisa e Extensão em Odontologia, Saúde Coletiva, Microbiologia Oral e \\ Biossegurança em Odontologia. No Curso de Graduação em Odontologia da UFSM, desenvolve \\ trabalhos em conjunto com o Departamento de Odontologia Restauradora, atuando \\ principalmente nos seguintes temas: aderência de microorganismos à superfícies não \\ descamáveis, dentifrícios fluoretados com concentração reduzida de flúor, pmsf, cariologia clínica \\ e biossegurança em Odontologia. É docente do Curso de Pós Graduação em Educação Ambiental, \\ do Centro de Ciências Rurais, da UFSM, na Área de Educação e Saúde, Membro da Sociedade \\ Brasileira de Pesquisa Odontológica (SBPqO) e do Grupo Brasileiro de Microbiologia Oral (GBMO).
}

\section{RESUMO}

Esse documento apresenta alguns resultados obtidos na Monografia de Conclusão do Curso de Pós-Graduação Lato Sensu Especialização em Educação Ambiental, edição realizada em 2008 e 2009 pela Universidade Federal de Santa Maria no Pólo de Panambi/RS. O presente trabalho utilizou a Língua Inglesa como ferramenta de sensibilização e mudanças de atitudes no ensino da educação ambiental com os alunos da Escola Estadual de Ensino Médio Agostinha Dill Condor/RS, utilizando ferramentas lúdicas, jogos e brincadeiras para promover educação ambiental, bem como verificar o conhecimento experiente na população escolar sobre as questões ambientais. Também realizou atividades com os alunos em língua inglesa relacionadas ao meio ambiente. Para atingir os objetivos propostos, foram realizados estudos bibliográficos, aplicados questionários para verificar o conhecimento prévio dos aprendizes, bem como materiais para a sensibilização dos alunos em relação à educação ambiental, como por exemplo, vídeos e textos informativos, jogos e atividades práticas. Os resultados demonstram que a educação ambiental trabalhada no âmbito escolar traz muitos conhecimentos e benefícios necessários aos aprendizes, os quais visam à sustentabilidade do Planeta. 
REMOA

\section{Monografias Ambientais (e-ISSN: 2236-1308)}

Palavras-chave: Educação Ambiental. Jogos. Brincadeiras. Língua Inglesa

\section{ABSTRACT}

This paper presents the main results of the Specialization Monograph of the Sensu Lato Post graduate Course on Environmental Education, edition held in 2008 and 2009 by Federal University of Santa Maria in Panambi. This paper aims to use the English language as a tool for sensitization and changes in attitudes in the teaching of environmental education with students from Escola Estadual de Ensino Médio Agostinha Dill Condor/RS, using playful tools, games and activities, to promote environmental education, as well as to verify the knowledge in the school population about environmental issues, and also promote activities, with students in English classes, related to the environment. To supply the proposed goals, bibliographical studies, questionnaires to check the students' knowledge, and also materials used to sensitize them to wards environmental education, such as videos and informational texts, games and practical activities, were done. The results show that the environmental education used in a school background, brings benefits and knowledge needed to students, which have the main purpose the sustain ability of the planet.

Keywords: Environmental Education. Games. Playful activities. English language

\section{INTRODUÇÃO}

Desde o início da história da humanidade as pessoas empregam jogos e brincadeiras para se socializarem, expressarem seus sentimentos, suas ações e para proporcionar alegria. Com o passar do tempo, os jogos e as brincadeiras foram se transformando, mas até hoje eles são considerados fonte de alegria e prazer. Ademais, com o avanço das teorias da educação, os jogos e as brincadeiras passaram a ser considerados como importantes alternativas metodológicas. Todavia é necessário o conhecimento das implicações da utilização do trabalho lúdico para que possam ser melhor aplicados ao ensino de maneira geral. Utilizando-se destas ferramentas, inseriu-se a educação ambiental no âmbito escolar, uma vez que para Pontalti (2005) a escola é o espaço social, bem como o local onde o aluno dá sequência ao seu processo de socialização, o qual se inicia em casa juntamente com seus familiares. É de suma importância a escola trabalhar o processo de formação, tanto social quanto ambiental dos seus educandos.

O presente trabalho visou sensibilizar as crianças da Escola Estadual de Ensino Médio Agostinha Dill, utilizando ferramentas lúdicas para promover educação ambiental. Na condição de professora de Língua Inglesa na escola, utilizei algumas atividades de Educação Ambiental, visando relacionar com a disciplina em questão. De acordo com Sato (2002) há diferentes formas de incluir a temática ambiental nos currículos escolares, experiências práticas, atividades fora de sala de aula, produção de materiais locais, projetos ou qualquer outra atividade que conduza os alunos a serem reconhecidos como agentes ativos no processo que norteia a política ambientalista. Cabe aos professores, por intermédio de prática interdisciplinar, propor novas metodologias que favoreçam a implementação da Educação Ambiental, partindo de exemplos de problemas atualizados. Dessa forma os objetivos deste trabalho foram: 
motivar as crianças através de vídeos abordando as questões ambientais; confeccionar tonéis para a coleta seletiva; verificar o conhecimento experiente na população escolar sobre as questões ambientais; promover atividades onde questões relacionadas ao lixo serão trabalhadas; promover uma trilha ecológica junto as rio Raiz, sensibilizando as crianças para os problemas ambientais existentes; inserir atividades em Língua Inglesa relacionadas à Educação Ambiental; criar um ambiental virtual para permitir aos alunos da $5 \underline{a}$ série 0 acesso a atividades lúdicas que promovam a Educação Ambiental; disponibilizar um CD contendo as atividades desenvolvidas, jogos e resultados obtidos no presente trabalho.

Nessa perspectiva, realizou-se uma pesquisa em ambiente virtual com alunos de uma $5 \underline{a}$ série do Ensino Fundamental sobre o perfil ambiental da escola, bem como sobre o conhecimento dos alunos quanto às questões ambientais. Esta pesquisa demonstrou o conhecimento dos aprendizes sobre o ambiente em que estão inseridos, bem como as atividades desenvolvidas na escola referentes a esse assunto.

\section{DESENVOLVIMENTO}

A presente pesquisa teve como foco a sensibilização e conscientização dos problemas ambientais, através de atividades lúdicas desenvolvidas nas aulas da disciplina de Língua Inglesa. Algumas atividades foram disponibilizadas num ambiente virtual de aprendizagem no endereço virtual http:// www.educacaonanet.com.br/professores/. Foi desenvolvida na Escola Estadual de Ensino Médio Agostinha Dill, uma vez que é o contexto em que trabalho. A Instituição situa-se no município de Condor/RS, e conta com uma infraestrutura adequada, possuindo uma ampla biblioteca, laboratório de informática com trinta (30) computadores, laboratório de ciências e de reciclagem de papel, sala de vídeo, ginásio de esportes e um amplo pátio onde as crianças brincam na hora do recreio. A escola também possui projetor de vídeo, data show para apresentações de trabalhos escolares desenvolvidos pelos alunos nas diversas disciplinas.

Os alunos que participaram da pesquisa são integrantes de uma $5 \underline{a}$ série, sendo esta composta por vinte e nove (29) alunos, destes, doze (12) meninos e dezessete (17) meninas, dos mais diferentes bairros da cidade.

A Pesquisa foi desenvolvida observando-se as seguintes etapas. Na primeira etapa foram realizados momentos de sensibilização com os alunos, através de vídeos educativos do You Tube sobre questões ambientais, sendo que um deles era em Inglês. Após assistirem aos vídeos, houve momentos de diálogo entre alunos e professora sobre os problemas ambientais apresentados, quando cada aluno teve a oportunidade de fazer a sua contribuição e sua análise crítica, bem como apresentar sugestões de ações pertinentes ao assunto.

Para complementar e registrar o momento de sensibilização, foram entregue aos educandos um texto informativo, sobre os 3 Rs, "reduzir, reaproveitar e reciclar", tempo de decomposição dos resíduos sólidos e dicas de como reutilizá-los.

Os alunos foram até o telecentro próximo à escola, onde cada um recebeu um login e uma senha para acesso ao ambiente. Após responderam virtualmente um questionário "Levantamento do perfil ambiental da escola, bem como o conhecimento dos alunos perante as questões ambientais", contendo sete (7) questões, destas, duas (2) eram fechadas e quatro (4) dissertativas. 


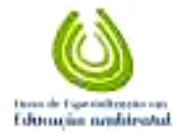

MELLO \& PERES, vol.(4), n4, p. 660-671, 2011.

REMOA Monografias Ambientais (e-ISSN: 2236-1308)

REMOA

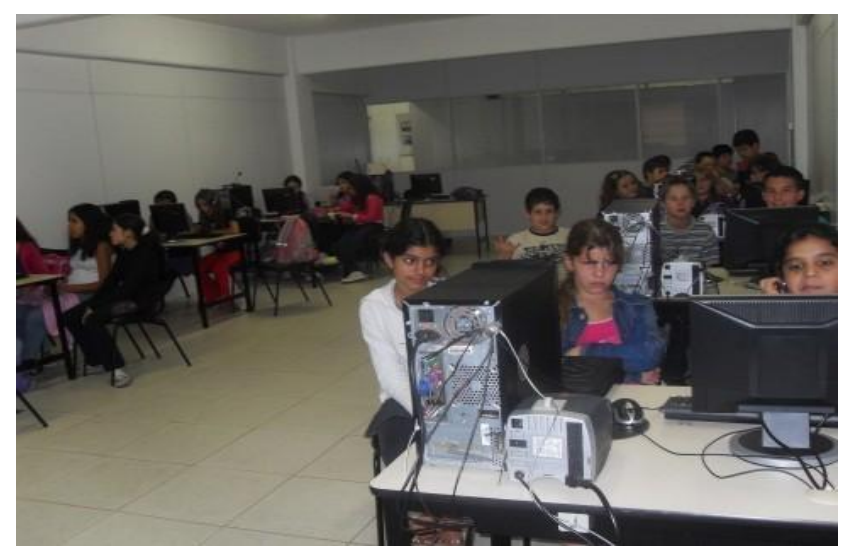

Figura 1: alunos realizando as atividades no ambiente virtual.

No ambiente EAD (MOODLE) foram disponibilizados diversos jogos virtuais relacionados com questões ambientais. Segue endereço dos respectivos jogos:

Jogo Coleta Seletiva - http://www.escolagames.com.br/jogos/coletaSeletiva/ Jogo em Inglês http://www.foxjogos.com/jogos-online/recycle

Jogo Tartaruga - http://www2.uol.com.br/ecokids/jogos/arca 01.htm

Jogo do Ratinho - http://iguinho.ig.com.br/jogo reciclagem.html

Jogo Lixo - http://www.jogosonlinegratis.org/jogoonline/ajudar-o-meio- ambiente/

No primeiro jogo os alunos obtiveram informações sobre a coleta seletiva e depois separaram os resíduos, arrastando-os para a lixeira correta. Fazer a coleta seletiva na própria casa e encaminhar os resíduos para a reciclagem é um jeito divertido de colaborar com a preservação do meio ambiente, uma vez que o jogo contribui com o desenvolvimento da consciência ecológica da criança, pois ela memoriza rapidamente as cores usadas na Coleta Seletiva e aprende como separar os resíduos para a reciclagem. Além disso, a cada avanço, ela recebe informações de fácil entendimento sobre os danos que esses resíduos causam à natureza, caso não sejam reciclados.

O segundo jogo era em inglês, o mesmo continha três latões de lixo todos com a identificação em inglês (glass, paper, plastic), sendo que o objetivo era colocar o lixo correto em cada latão de acordo com um tempo estipulado para cada lixeira. Além de aprender a reciclar os alunos também tiveram contato com a língua inglesa.

O terceiro jogo era o da tartaruga, onde uma tartaruga deveria se livrar de sacos de lixo jogados no mar, conscientizando a todos de que os mesmos são fatais para as tartarugas marinhas.

O quarto foi o jogo do ratinho, em que a proposta era ajudar o ratinho a separar o lixo deixado por seu amigo, colocando-o na lixeira correta, sendo que as lixeiras são: plástico, papel, metal, vidro e orgânico. São destinados 45 segundos para jogar o maior número nas lixeiras certas.

Como última opção, o jogo lixo, em o principal objetivo era ajudar o meio ambiente, educando as crianças sobre a importância de limpar as ruas, as cidades e jogar lixo no lixo.

Primeiramente se deveria escolher um personagem para representar o jogador, após o mesmo deveria correr em uma pista e recolher o maior número de latas, casca de banana e outros itens 


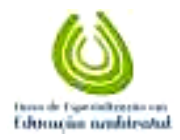

MELLO \& PERES, vol.(4), n4, p. 660-671, 2011.

REMOA

\section{Monografias Ambientais (e-ISSN: 2236-1308)}

que encontrasse no caminho. Em outra etapa plantar o maior número de árvores possíveis no tempo determinado pelo jogo. Ao final aparecia o número de pontos que se adquiriu com as atividades.

No ambiente EAD foram disponibilizados três (3) vídeos: Projeto meio ambiente "lixo" Escola Plácido de Castro, Trabalho de inglês sobre meio ambiente, Trabalho sobre meio ambiente (paródia my humps). Foi dado o prazo de uma semana para que os alunos assistissem aos três vídeos, podendo acessar nos computadores da escola, no telecentro ou até mesmo em suas casas. Após este prazo foi distribuída uma folha, contendo imagens de um dos vídeos assistidos pelos alunos, o qual era em inglês, e desta forma os aprendizes deveriam fazer a tradução da mensagem, sendo a mesma avaliada na disciplina de Língua Inglesa.

Foi realizada uma saída de campo orientada no rio Raiz, localizado na área urbana da cidade, conforme figuras a seguir:

Aconteceu um diálogo entre os educandos e a professora a respeito dos problemas ambientais visualizados no decorrer da visita, nas margens e no leito do rio no trajeto delimitado.

A turma realizou a pintura dos tonéis para a realização e implantação da coleta seletiva. Segue figura 2 que registra a realização da atividade.

E por último foi reaplicado o questionário, desta vez em forma impressa.



Figura 2: alunos pintando os tonéis para a coleta seletiva. 
Este capítulo apresenta os resultados da pesquisa realizada, sendo que os instrumentos utilizados para coleta de dados foram vídeos do You Tube e saída de campo. Os dados possibilitaram conhecer a opinião e medir os conhecimentos dos alunos em relação às questões ambientais, em especial aos resíduos sólidos urbanos.

Inicialmente houve um momento de sensibilização no qual foram disponibilizados no ambiente virtual os seguintes vídeos: Projeto Meio Ambiente "lixo" Escola Plácido de Castro; Trabalho de Inglês sobre o meio ambiente; Trabalho sobre meio ambiente (paródia my humps). Alguns alunos assistiram aos vídeos em casa, outros foram até o telecentro da cidade, e também foi disponibilizado um momento na sala de aula. Após assistir aos três vídeos, foram feitas discussões sobre as temáticas abordadas nos vídeos, onde os educandos contribuíram com relatos sobre sua realidade local.

Neste mesmo dia foi distribuído um texto sobre os $3 \mathrm{Rs}$, reduzir, reaproveitar e reciclar, tempo de decomposição dos resíduos sólidos e dicas de como reutilizá-los, sendo que o mesmo foi lido em conjunto. Durante as discussões percebeu-se que os alunos não tinham conhecimento sobre o tempo de decomposição dos resíduos sólidos citados no texto, bem como das dicas de reutilização apresentadas no mesmo. Os dados apresentados no texto trouxeram informações novas para os alunos, aos quais foi solicitado que repassassem essas informações para o maior número de pessoas possível, pois desta forma cada um estaria fazendo a sua parte perante o meio ambiente em que estão inseridos, contribuindo para a sustentabilidade do nosso Planeta.

Dando continuidade à aplicação das atividades de Educação Ambiental, foi disponibilizado no ambiente virtual um questionário. Os alunos responderam a seguinte pergunta: Na escola existe o processo de separação do lixo produzido pela comunidade escolar? Nessa questão trabalhouse com as opções sim ou não. Os resultados estão apresentados no gráfico a seguir.

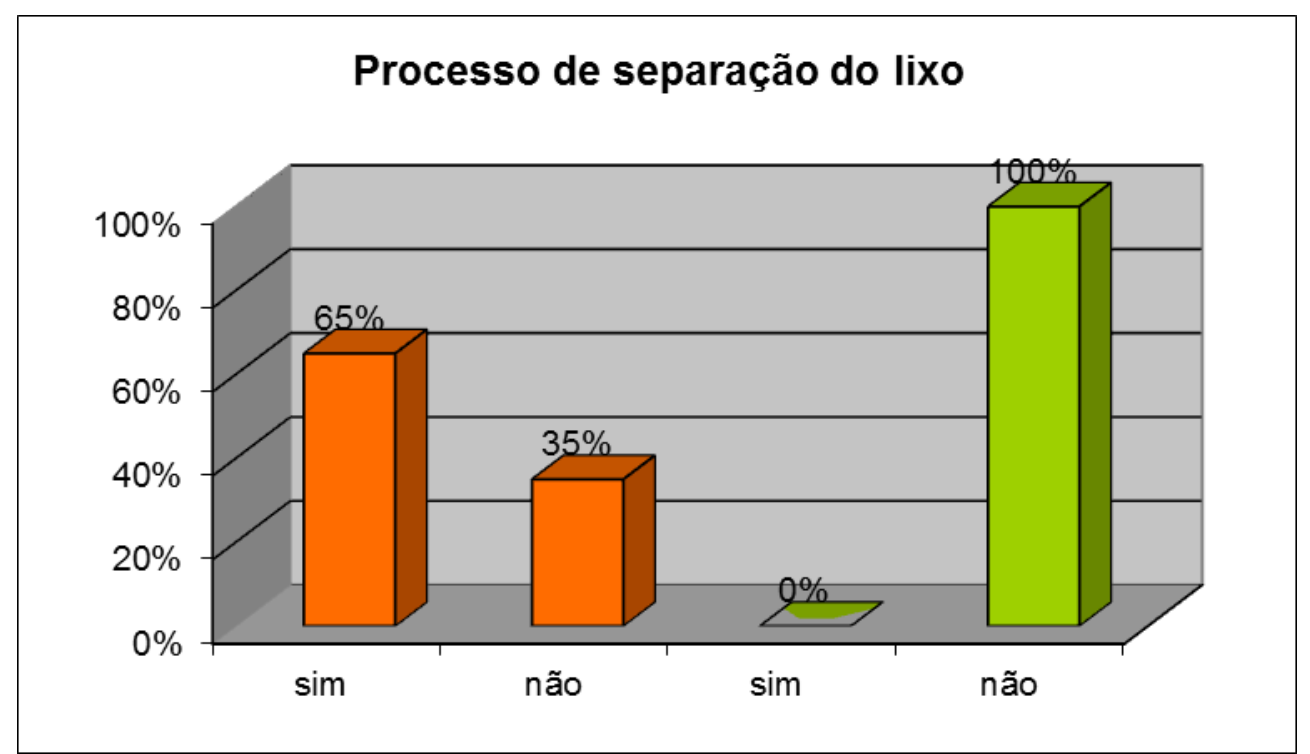

Gráfico 1: Na escola existe o processo de separação do lixo produzido pela comunidade escolar?

Como demonstrado no gráfico, no primeiro questionário aplicado, quando os alunos não tinham muito conhecimento sobre o assunto, $65 \%$ deles responderam que na escola existia o processo de separação do lixo produzido pela comunidade escolar, já 35\% optaram pela assertiva 
"não". Após trabalho realizado com os mesmos, $100 \%$ da turma percebeu que na verdade não existe nenhum processo de separação do lixo na escola.

Com uma nova visão a respeito de aspectos relacionados aos resíduos sólidos, os educandos perceberam a necessidade do processo de separação do lixo produzido no ambiente escolar, confeccionando assim latões de lixo com a designação correta de cada resíduo, uma vez que ações ambientalmente corretas devem ser assimiladas desde cedo pelas crianças e devem fazer parte do seu dia-a-dia, passando a conviver com estas experiências nos mais distintos âmbitos em que se encontrarem.

Como segunda questão os educandos responderam ao seguinte: A escola realiza visitas a campo, para trabalhar a realidade local sobre as questões ambientais? Nessa questão também se trabalhou com as opções sim ou não. Segue gráfico:

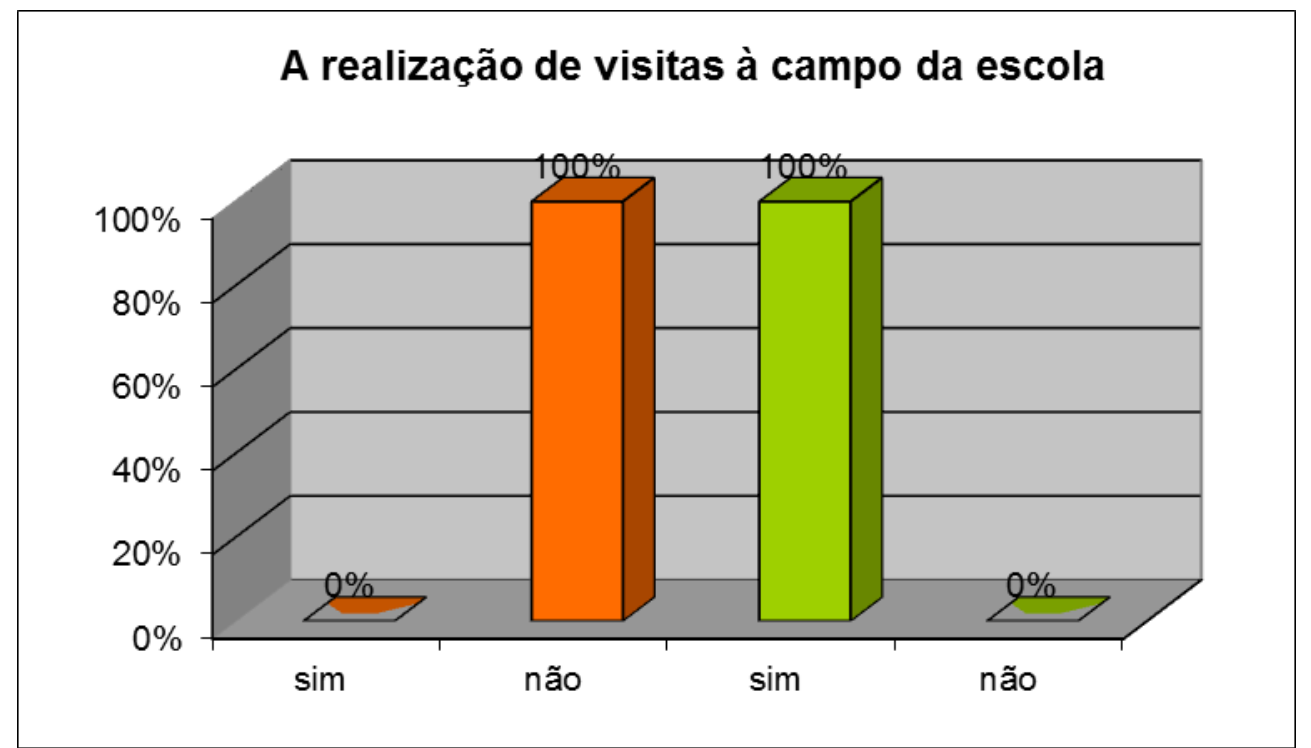

Gráfico 2: A escola realiza visitas a campo, para trabalhar a realidade local sobre as questões ambientais?

De acordo com o gráfico, percebe-se que no primeiro questionário aplicado, a totalidade dos aprendizes representada por $100 \%$ da turma, respondeu que a escola não realiza visitas a campo visando trabalhar a realidade local sobre as questões ambientais, uma vez que após a saída de campo orientada no rio Raiz, todos os alunos optaram pela alternativa sim, demonstrando assim a realização da primeira visita a campo realizada pela escola com estes alunos, visando trabalhar a realidade local sobre as questões ambientais.

A terceira questão era a seguinte: $O$ que é coleta seletiva? Segue quadro 1 com algumas respostas.

\begin{tabular}{|l|l|}
\hline \multicolumn{1}{|c|}{ Primeiro questionário aplicado } & \multicolumn{1}{|c|}{ Segundo questionário aplicado } \\
\hline É recolher lixo reciclável. & $\begin{array}{l}\text { É o termo utilizado para o recolhimento } \\
\text { separado do lixo reciclável e o não } \\
\text { reciclável. }\end{array}$ \\
\hline É a coleta do lixo. & $\begin{array}{l}\text { É separar o lixo para que seja enviado } \\
\text { para reciclagem, não misturando materiais } \\
\text { recicláveis com o resto do lixo. }\end{array}$ \\
\hline
\end{tabular}




\begin{tabular}{|l|l|}
\hline $\begin{array}{l}\text { É uma coleta de lixo que um lixo é } \\
\text { separado do outro. }\end{array}$ & Consiste na coleta do lixo separado. \\
\hline É a coleta das regiões. & É separar o lixo seco do orgânico. \\
\hline Eu não faço ideia. & Recolhimento do lixo separado. \\
\hline
\end{tabular}

Quadro 1: Considerações dos alunos quanto à coleta seletiva antes e após a sensibilização.

Como demonstra o quadro 1 , os alunos no início da pesquisa não tinham conhecimento necessário a respeito do que é a coleta seletiva, de que maneira a mesma acontece, sendo que após o trabalho realizado com os mesmos, através de textos e vídeos explicativos e também de jogos virtuais sobre a coleta seletiva, todos os aprendizes demonstraram ter obtido o conhecimento necessário a respeito do assunto, sendo muito satisfatório.

A pergunta de número quatro foi: $O$ que significam os 3 Rs? Segue quadro2 com algumas respostas.

\begin{tabular}{|l|l|}
\hline \multicolumn{1}{|c|}{ Primeiro questionário aplicado } & \multicolumn{1}{c|}{ Segundo questionário aplicado } \\
\hline Não sei. & Reduzir, reaproveitar e reciclar. \\
\hline Significa os 3 rios. & Reduzir, reaproveitar e reciclar. \\
\hline 3 toneladas de lixo. & Reduzir, reaproveitar e reciclar. \\
\hline Eu nunca vi falar isso. & Reduzir, reaproveitar e reciclar. \\
\hline Sei lá. & Reduzir, reaproveitar e reciclar. \\
\hline
\end{tabular}

Quadro 2: Considerações dos alunos sobre o significado dos 3 Rs antes e após a sensibilização.

Nenhum aluno da pesquisa soube previamente responder o que significam os 3 Rs, para eles essa pergunta era totalmente desconhecida, através destas perspectivas percebe-se a necessidade de trazer para os aprendizes questões como essas que para nós adultos parecem ser tão óbvias, mas para os alunos são um tanto complexas. Após atividades a respeito desse assunto, todos os alunos responderam corretamente a questão.

A quinta pergunta: Quais são os tipos de lixo e suas respectivas cores para reciclagem?

Segue quadro 3 com algumas respostas.

\begin{tabular}{|l|l|}
\hline \multicolumn{1}{|c|}{ Primeiro questionário aplicado } & \multicolumn{1}{c|}{ Segundo questionário aplicado } \\
\hline Não sei. & $\begin{array}{l}\text { Marrom- orgânico, Amarelo- metal, Azul- } \\
\text { papel, Verde- vidro, Vermelho- plástico. }\end{array}$ \\
\hline $\begin{array}{l}\text { Amarelo é plástico, marrom é vidro e } \\
\text { verde é orgânico. }\end{array}$ & $\begin{array}{l}\text { Metal é amarelo, papel é azul, vidro é } \\
\text { verde, plástico é vermelho e orgânico é } \\
\text { marrom. }\end{array}$ \\
\hline Papel = azul. & $\begin{array}{l}\text { Azul = papel, Verde = vidro, Marrom } \\
\text { orgânico, Vermelho = plástico, Amarelo } \\
\text { metal. }\end{array}$ \\
\hline Não faço ideia. & $\begin{array}{l}\text { Marrom- orgânico, Amarelo- metal, Azul- } \\
\text { papel, Verde- vidro, Vermelho- plástico. }\end{array}$ \\
\hline Não lembro. & $\begin{array}{l}\text { Marrom- orgânico, Amarelo- metal, Azul- } \\
\text { papel, Verde- vidro, Vermelho- plástico. }\end{array}$ \\
\hline
\end{tabular}

Quadro 3: Considerações dos alunos junto aos tipos de lixo e suas respectivas cores para reciclagem antes e após a 
REMOA

\section{Monografias Ambientais (e-ISSN: 2236-1308)}

sensibilização.

Através das respostas pode-se observar que alguns alunos podem até saber algumas das cores, mas não sabem relacioná-las de forma correta, ou não lembram. As atividades desenvolvidas sobre as cores que representam cada lixo foram muito bem aceitas pelos alunos, como por exemplo, jogos, e até mesmo a pintura das lixeiras feita pelos próprios alunos. Com isso aprenderam de forma rápida e prazerosa uma atitude muito importante para a reciclagem, e para o meio ambiente.

A sexta questão foi: Qual é o tempo de decomposição das embalagens pet?

Segue quadro 4 com algumas respostas.

\begin{tabular}{|l|l|}
\hline \multicolumn{1}{|c|}{ Primeiro questionário aplicado } & \multicolumn{1}{c|}{ Segundo questionário aplicado } \\
\hline 50 a 100 anos. & Mais de 100 anos. \\
\hline 450. & Mais de 100 anos. \\
\hline Não sei. & Mais de 100 anos. \\
\hline Indeterminado tempo & Mais de 100 anos. \\
\hline 100.000 & Mais de 100 anos. \\
\hline
\end{tabular}

Quadro 4: Considerações dos alunos sobre o tempo de decomposição das embalagens pet antes e após a sensibilização.

Nenhum dos aprendizes tinha conhecimento do tempo de decomposição das embalagens pet, o qual adquiriram através de trabalho realizado com os mesmos.

A última pergunta foi: Qual é o tempo de decomposição de uma goma de mascar (chiclete)? Segue quadro 5 com algumas respostas.

\begin{tabular}{|l|l|}
\hline \multicolumn{1}{|c|}{ Primeiro questionário aplicado } & \multicolumn{1}{c|}{ Segundo questionário aplicado } \\
\hline 3 anos. & 5 anos. \\
\hline 30 dias. & 5 anos. \\
\hline Não sei, quero aprender, deve ser legal. & 5 anos. \\
\hline 1 ano & 5 anos. \\
\hline 5 anos & 5 anos. \\
\hline
\end{tabular}

Quadro 5: Considerações dos alunos sobre o tempo de decomposição de uma goma de mascar (chiclete), antes e após a sensibilização.

Apenas um aluno acertou previamente o tempo de decomposição de uma goma de mascar, os demais ficaram surpresos quando souberam o tempo correto, pois achavam que era menos tempo.

Na atividade subsequente os aprendizes tiveram a oportunidade de praticar vários jogos no ambiente virtual, contendo questões de extrema importância para o meio ambiente. Enquanto jogavam, pode-se perceber a utilização de estratégias para conseguir alcançar o objetivo proposto de cada jogo, uma vez que os jogos criam estratégias e que ao brincar as crianças formulam e resolvem problemas, elaboram e cumprem regras, contribuindo dessa maneira para 


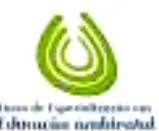

REMOA
MELLO \& PERES, vol.(4), n4, p. 660-671, 2011.

Monografias Ambientais (e-ISNN: 2236-1308)

o seu desenvolvimento afetivo, social e intelectual.

Essas estratégias podem ser transpostas para qualquer outro momento de aprendizagem, sendo que se pode perceber a rápida aprendizagem dos alunos sobre os assuntos apresentados nos jogos, bem como a satisfação dos mesmos na realização das atividades.

Em um terceiro momento os aprendizes receberam uma mensagem impressa em inglês contendo imagens de um dos vídeos assistidos pelos mesmos, realizaram a tradução da mensagem em duplas utilizando o dicionário e após entregaram o trabalho como forma de avaliação. Através desta atividade pode-se perceber a motivação deles ao realizarem o trabalho, uma vez já estavam familiarizados com aquelas imagens, aquele contexto, ficando mais fácil o decorrer da mesma. Como enfatiza Piaget, a criança constrói seu conhecimento de forma ativa na interação com o ambiente, apoderando-se de um conhecimento se agir sobre ele, pois aprender significa modificar, inventar e descobrir.

No quarto momento foi realizada uma saída de campo orientada no rio Raiz, esta atividade foi de extrema importância, uma vez que visou trabalhar a realidade local do município sobre as questões ambientais, pois para muitos dos alunos ainda era desconhecida a situação em que se encontra o meio ambiente.

Foi solicitado aos alunos, após o diálogo, que se reunissem em pequenos grupos, e foram sorteados dois tipos de atividades: produção de paródia e texto, ambos deveriam enfocar os problemas ambientais visualizados na saída de campo, bem como alternativas visando à sustentabilidade do Planeta. Um dos textos realizados pelos alunos, bem como uma paródia, encontram-se no Anexo 2, no CD.

Através das percepções dos alunos surge um quinto momento, em que aconteceu um diálogo entre os educandos e a professora, instigando a responsabilidade que cada um deve ter perante as questões ambientais, já que foram citados os problemas relativos ao meio ambiente, visualizados no decorrer da visita tanto no leito do rio, quanto na margem do trajeto delimitado. Os aprendizes constataram que os atos de cada um refletem sobre o futuro de toda a humanidade e que a educação ambiental deve ser trabalhada na escola de forma interdisciplinar, uma vez que Sato (2002) diz que essa "sustenta todas as atividades e impulsiona os aspectos físicos, biológicos, sociais e culturais dos seres humanos". Sendo assim, apresenta-se como uma peça importante no currículo escolar.

Após o diálogo, os alunos divididos em grupos realizaram uma paródia ou uma produção de texto, sendo que foi designado o que cada grupo faria através de sorteio, os trabalhos encaminhados deveriam enfocar os problemas ambientais visualizados na saída de campo, bem como alternativas visando a sustentabilidade do Planeta.

Como se pode perceber na paródia realizada pelos alunos a partir da música Shimbalaiê, está visível a preocupação dos alunos quanto ao meio ambiente, visando o trabalho coletivo para a solução de muitos dos problemas enfrentados na atualidade, como por exemplo, a poluição.

O texto realizado pelos alunos com o título "O lixo", dá ênfase a questões relacionadas à poluição, enfatizando a extrema importância da reciclagem para um mundo melhor.

No sexto momento a turma foi dividida em quatro (4) grupos, sendo que cada um deles foi responsável por pintar um tonel de lixo de uma das cores que corresponde ao tipo de resíduo sólido. Para eles este ato foi muito significante, pois adquiriram experiências e/ou vivências que não seriam possíveis de outra forma. 


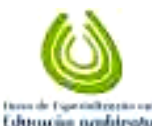

MELLO \& PERES, vol.(4), n4, p. 660-671, 2011.

REMOA

Monografias Ambientais (e-ISSN: 2236-1308)

\section{CONCLUSÃO}

O objetivo geral deste trabalho foi utilizar a Língua Inglesa como ferramenta de sensibilização e mudanças de atitudes no ensino de Educação Ambiental com as crianças da Escola Estadual de Ensino Médio Agostinha Dill, utilizando ferramentas lúdicas para promovê-la.

Os objetivos específicos foram alcançados, isto é, as crianças demonstraram interesse ao assistir aos vídeos, questionando sobre os aspectos ambientais abordados nos mesmos, assim como relatos de ações importantes para a preservação do meio ambiente sustentável.

Para avaliar o conhecimento da população escolar quanto às questões ambientais, foi aplicado um questionário contendo duas (2) questões fechadas e cinco (5) abertas, sendo este aplicado antes e após o momento de sensibilização. Os resultados alcançados foram significativos, uma vez que os alunos demonstraram um grande avanço relacionado ao conhecimento prévio que possuíam e o adquirido no decorrer do trabalho.

Com a finalidade de sensibilizar e promover mudanças de atitudes no ensino da Educação Ambiental foi oportunizada aos alunos uma saída de campo "trilha ecológica", na qual os alunos tiveram a oportunidade de identificar os problemas ambientais locais às margens do rio Raiz próximo a escola, relatando para a turma o que tinham visto e também o que poderiam fazer para mudar situações, propondo ações reais e imediatas, possíveis de serem realizadas tais como, retirar as roupas vistas nas margens do rio, as garrafas pets, entre outras e também fazer campanha para conscientizar a população em geral da importância de manter limpa a água do rio que atravessa a cidade que habitam.

Foi realizada a pintura de tonéis para a coleta seletiva dos resíduos sólidos com a identificação em língua inglesa, o trabalho foi significativo, uma vez que todos os alunos participaram ativamente da atividade proposta, sentindo-se motivados no decorrer do trabalho que foi realizado. A turma se sentiu privilegiada por ser a pioneira da escola a ter em sua sala os tonéis de resíduos sólidos identificados na língua inglesa.

Constatou-se a importância da Educação Ambiental ser inserida no contexto escolar de forma interdisciplinar, uma vez que pode ser trabalhada em todas as disciplinas, e através de jogos e/ou brincadeiras pode ficar mais fácil a aprendizagem.

Foi válida a reflexão dos professores que ainda não fazem uso das atividades lúdicas, quanto à importância das mesmas em sala de aula, para que possam por em prática aulas mais descontraídas, prazerosas, e com estímulo, viabilizando a inserção da Educação Ambiental.

Através dessas atitudes, desencadear-se-á uma aprendizagem mais significativa e relevante para os aprendizes.

É as transformações na educação que promovem hoje novas atitudes, possibilitando ao professor e ao aluno aprenderem juntos, construírem caminhos de sucesso e, desta forma, contribuindo para que se melhore o sistema educacional em que se está inserido, promovendo ações que visem a sustentabilidade do Planeta. 


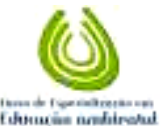

\section{MELLO \& PERES, vol.(4), n4, p. 660-671, 2011. Monografias Ambientais (e-ISSN: 2236-1308)}

REMOA

\section{REFERÊNCIAS}

ANDRADE, D. F. Implementação da Educação Ambiental em escolas: uma reflexão. In: Fundação Universidade Federal do Rio Grande. Revista Eletrônica do Mestrado em Educação Ambiental, v. 4.out/nov/dez 2000.

ALMEIDA FILHO, J. C. P. de. Dimensões comunicativas no ensino de línguas. Campinas, São Paulo: Pontes, 1993.

ANTUNES, C. Jogos para a estimulação das múltiplas inteligências. Petrópolis, RJ: Vozes, 1999.

BIZERRIL, M. X. A. FARIA, D. S. Percepção de professores sobre educação ambiental no ensino fundamental. Disponível em <http://www.rbep.inep.gov.br> Acesso em 15/11/2010.

BRASIL. Ministério da Educação. Secretaria de Educação Fundamental. Parâmetros Curriculares Nacionais: terceiro e quarto ciclos: apresentação dos temas transversais. Brasília: MEC/SEF, 1998. 436 p.

DIAS, G. F. Educação Ambiental: princípios e práticas. São Paulo, Gaia, 1992.

FREIRE, P. Pedagogia da autonomia: saberes necessários à pratica educativa. São Paulo: Paz e Terra, 1996.

JACOBI, P. Educar para a sustentabilidade: complexidade, reflexividade, desafios In: Revista Educação e Pesquisa, vol. 31/2 mai/ago 2005, F-USP.

PASSERINO, L. M. Disponível em:<http://www.c5.cl/tise98/html/trabajos/jogosed/index.htm> Acesso em: 03/07/2010

PONTALTI, E. S. Projeto de Educação Ambiental: Parque Cinturão Verde de Cianorte. Disponível me: http://www.apromac.org.br. Acesso em: 20/03/2008.

REGO, T. C. Vygotsky: uma perspectiva histórico-cultural da educação. Petrópolis, RJ: Vozes, 1995.

REVERBEL, O. Jogos teatrais na escola: atividades globais de expressão. São Paulo: Scipione, 1996. (Série: Pensamentos e Ação no Magistério)

RIBEIRO, L. E. P. Para casa ou para escola? São Paulo: Didática Paulista, 1999.

SANTA ROSA, N. S. Brinquedos e brincadeiras. São Paulo: Moderna, 2001. (Coleção arte e raízes).

SANTOS, S. M. P. dos. Brinquedoteca: sucata vira brinquedo. Porto Alegre: Artes Médicas, 1995.

SANTOS, S. S. dos. The Strategic Language Learner- a construction that needs reconsideration. IN: ROTTAVA, L. ; LIMA, M. dos S. Lingüística aplicada: relacionando teoria e prática no ensino de línguas. ljuí: Unijuí, 2004. p. 165-186.

SATO, M. Educação Ambiental. São Carlos: Rima, 2002.

VOLPATO, G. Jogo, brincadeira e brinquedo: Uso e significados no contexto escolar e familiar. Florianópolis, SC: Cidade Futura, 2002.

VYGOTSKY, L. S. A formação social da mente: o desenvolvimento dos processos psicológicos superiores. São Paulo: Martins Fontes, 2003.

ZANLUCHI, F. B. O brincar e o criar: as relações entre atividade lúdica, desenvolvimento da criatividade e educação. Londrina: O Autor, 2005. 